\title{
Segmental migration of trunk neural crest: time-lapse analysis reveals a role
}

\section{for PNA-binding molecules}

\author{
Catherine E. Krull1,*, Andres Collazo ${ }^{2}$, Scott E. Fraser ${ }^{2}$ and Marianne Bronner-Fraser ${ }^{1}$ \\ ${ }^{1}$ Developmental Biology Center, UC Irvine, Irvine CA 92717, USA \\ 2 Division of Biology, California Institute of Technology, Pasadena CA 91125, USA \\ *Author for correspondence (email: cekrull@uci.edu)
}

\section{SUMMARY}

Trunk neural crest cells migrate through the somites in a striking segmental fashion, entering the rostral but not caudal sclerotome, via cues intrinsic to the somites. Attempts to define the molecular bases of these cues have been hampered by the lack of an accessible assay system. To examine trunk neural crest migration over time and to perturb candidate guiding molecules, we have developed a novel explant preparation. Here, we demonstrate that trunk regions of the chicken embryo, placed in explant culture, continue to develop apparently normally for 2 days. Neural crest cells, recognized by prelabeling with DiI or by poststaining with the HNK-1 antibody, migrate in the somites of the explants in their typical segmental pattern. Furthermore, this paradigm allows us to follow trunk neural crest migration in situ for the first time using lowlight-level videomicroscopy. The trajectories of individual neural crest cells were often complex, with cells migrating in an episodic mode encompassing forward, backward and lateral movements. Frequently, neural crest cells migrated in close-knit groups of $2-4$ cells, moving at mean rates of migration of 10-14 $\mu \mathrm{m} / \mathrm{hour}$. Treatment of the explants with the lectin peanut agglutinin (PNA) both slowed the rate and altered the pattern of neural crest migration. Neural crest cells entered both the rostral and caudal halves of the sclerotome with mean rates of migration ranging from 6 to $13 \mu \mathrm{m} / \mathrm{hour}$. These results suggest that peanut agglutinin-binding molecules are required for the segmental patterning of trunk neural crest migration. Because this approach permits neural crest migration to be both observed and perturbed, it offers the promise of more direct assays of the factors that influence neural crest development.

Key words: somite, explant culture, videomicroscopy, avian, neural crest, PNA

\section{INTRODUCTION}

Neural development involves the orchestration of various processes to generate patterns of cellular architecture and synaptic connectivity that are required for mature function. Precursor cells must migrate to their target regions, differentiate into numerous neuronal and non-neuronal derivatives, and form specific connections with their neighbors. A model system that has numerous advantages for studying these early developmental events is the avian neural crest. Neural crest cells emigrate from the neural tube shortly after its closure and navigate along well-characterized pathways to populate numerous derivatives, including the sensory and sympathetic ganglia (LeDouarin, 1982; Weston, 1970). Because they are well-characterized and accessible to experimental manipulation, neural crest cells have emerged as one of the major systems for studies of cell migration and patterning in the developing nervous system.

In the trunk region, neural crest cell migration is intimately linked to the development of the somites. Neural crest cells first migrate into an extracellular matrix-rich space between the neural tube and the epithelial somites (Loring and Erickson,
1987; Newgreen, 1989). Concomitant with early neural crest migration, somitic cells begin to segregate into two compartments: the dorsolateral portion gives rise to the dermomyotome; whereas, the ventromedial portion undergoes an epithelial-mesenchymal transformation to become the sclerotome (Keynes and Stern, 1988; Ordahl, 1993). Neural crest cells invade and migrate through the sclerotome in a segmental pattern, moving only through the rostral, but not caudal half (Rickmann et al., 1985). The cues that guide this segmental migration may influence other cell types; e.g. motor and sensory axons extend exclusively through the rostral somitic sclerotome (Keynes and Stern, 1984; Teillet et al., 1987).

The well-documented pattern of neural crest migration has served as a backdrop for studies of the underlying molecular mechanisms. Various cell surface and extracellular matrix (ECM) molecules are distributed along the pathways of migrating neural crest cells (Erickson and Perris, 1993). For example, laminin and fibronectin are prominent in the basal laminae of the neural tube, ectoderm and somites, where they are uniformly and diffusely localized within the sclerotome (Krotoski et al., 1986; Newgreen and Thiery, 1980). Numerous studies have shown that these molecules provide permissive 
substrata for neural crest migration in vitro (Erickson and Perris, 1993). Other molecules may play an inhibitory role, preventing neural crest cells from entering particular areas of the developing embryo (Tosney and Oakley, 1990; Oakley et al., 1994). Some candidate inhibitory molecules that are selectively distributed in the caudal sclerotome include T-cadherin (Ranscht and Bronner-Fraser, 1991), chondroitin sulfate proteoglycans (Oakley and Tosney, 1991; Perris et al., 1991) and peanut agglutinin (PNA)-binding molecules (Stern et al., 1986; Davies et al., 1990; Oakley and Tosney, 1991).

Despite numerous studies that have characterized the migratory patterns of neural crest cells relative to the distribution of candidate molecules capable of influencing these cells in vitro (Erickson and Perris, 1993), little is known about the molecules that guide neural crest cells in vivo. At cranial levels, perturbation experiments have implicated integrins (Bronner-Fraser, 1985, 1986), numerous ECM molecules (Poole and Thiery, 1986; Bronner-Fraser, 1988; Lallier and Bronner-Fraser, 1988) and cell adhesion molecules (BronnerFraser et al., 1992) as playing a functional role in the initiation of neural crest migration. Similar perturbation attempts have been unsuccessful, however, in the trunk region (BronnerFraser, 1993). This could reflect intrinsic differences in cranial and trunk neural crest cells, environmental differences in the guidance cues present at the two levels, or differences in the accessibility to perturbing reagents within these regions. Furthermore, previous studies on neural crest migration have relied solely upon the assessment of static images, raising the possibility that subtle alterations in neural crest migratory behavior could easily have been missed. Therefore, a dynamic analysis of trunk neural crest migration is required to distinguish between these alternatives.

To this end, we have developed a novel explant preparation that allows direct visualization of neural crest migration in normal living tissue. Here, we demonstrate that trunk regions of the chicken embryo, excised and placed in explant culture, appear to continue normal development for up to 2 days. Neural crest cells, prelabeled either with the vital dye DiI (Serbedzija et al., 1989) or poststained with the HNK-1 antibody, migrate in their typical segmental fashion in the rostral sclerotome. The morphological and molecular properties of the somites also seem to remain intact. Furthermore, this explant system permits neural crest cell migration to be followed in a relatively intact system using low-light-level videomicroscopy. This provides a unique opportunity to examine by direct observation both normal migratory behavior and the effects of reagents that perturb molecules that have been proposed to influence trunk neural crest migration. Our analyses show that treatment of trunk explants with the lectin PNA results in neural crest cells migrating in both the rostral and caudal regions of the sclerotome, suggesting that PNAbinding molecules are required for the segmental patterning of trunk neural crest migration.

\section{METHODS AND MATERIALS}

\section{Embryos}

Fertile White Leghorn chick eggs were acquired from local suppliers (Hy-line International) and incubated at $38^{\circ} \mathrm{C}$ until approximately stage 11-12 of development (Hamburger and Hamilton, 1951). Eggs were rinsed with $70 \%$ alcohol, $3 \mathrm{ml}$ of albumin was removed prior to cutting a window through each shell and a solution of $10 \%$ India ink (Pelikan) in Howard Ringer's solution was applied below the blastodisc to visualize the embryos.

\section{Culture preparation}

After careful removal of the vitelline membrane using a fine tungsten needle, a solution of DiI (1,1'-dioctadecyl-3,3,3',3'-tetramethyl indocarbocyanine percholorate; Molecular Probes) in isotonic sucrose was injected into the lumen of the neural tube of each embryo (Serbedzija et al., 1989). We verified that the neural tube, but not other structures, was labeled immediately after injection with DiI. Eggs were resealed with adhesive tape and incubated at $38^{\circ} \mathrm{C}$ for 5 hours.

After incubation, embryos were removed into Ringer's solution under a sterile hood. A region of the trunk, stretching from the fifth to the eleventh most recently formed somites (somites V-XI; Ordahl, 1993) was carefully dissected using tungsten needles. Transverse incisions were made just caudal to somite $\mathrm{V}$ and just rostral to somite XI. To free the tissue, incisions were made perpendicular to the first, extending longitudinally and lateral to somites V-XI. The resulting explant contained the neural tube including presumptive neural crest cells, multiple pairs of discrete somites and other associated structures, including ectoderm and endoderm.

Explant cultures of the trunk regions $(n=70)$, using Millicell inserts (Millipore) and six-well culture plates (Falcon), were created using a modification of a protocol kindly provided by Dr James Vaughn and colleagues (Barber et al., 1993). The ventral surface was placed on the Millicell polycarbonate membrane, leaving the dorsal surface of each explant exposed to the atmosphere. The Millicell insert was underlaid with defined culture medium composed of Neurobasal medium (Gibco), supplemented with B27 (Gibco) and $0.5 \mathrm{mM} \mathrm{L-}$
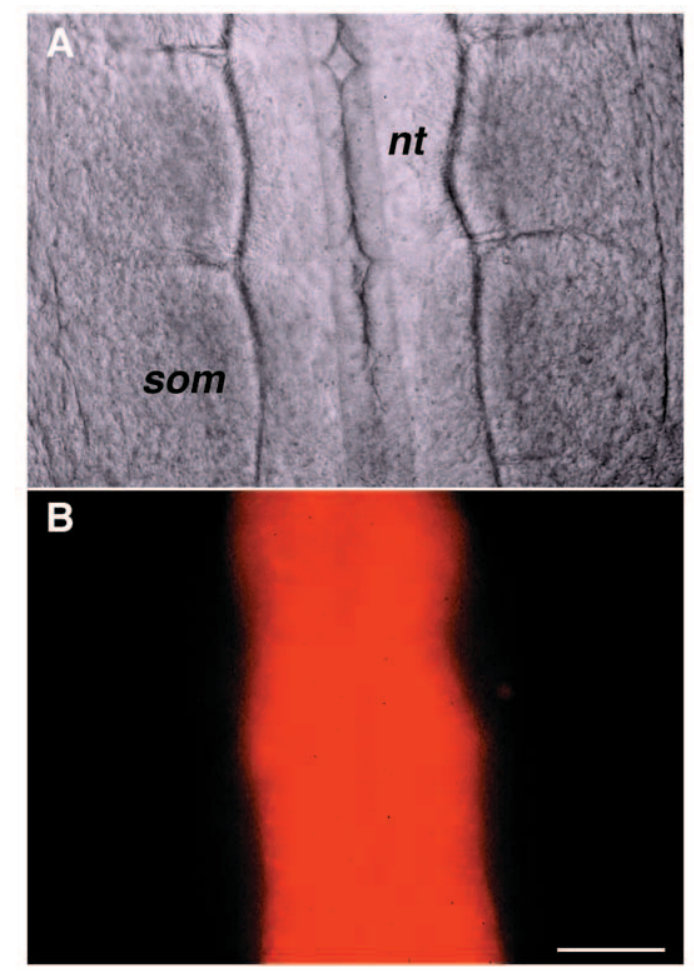

Fig. 1. Morphology and DiI labeling of the neural tube in trunk explants, immediately after placement into culture, 5 hours after DiI injection. (A) Bright-field micrograph of trunk explant. Somitic tissue and the neural tube are discrete structures. (B) In the same field as A, DiI labeling is confined to the neural tube. nt, neural tube; som, somite. Scale bar, $50 \mu \mathrm{m}$. 
glutamine (Sigma). A maximum of three explants were placed in each culture insert. The correct placement and geometry of each explant was verified using a microscope with epifluorescence optics and recorded photographically. Those explants that were folded and distorted in shape during placement onto the inserts were discarded from further analysis. As controls, DiI-labeled intact embryos were incubated in parallel with the explant cultures.

The explant cultures were incubated at $38^{\circ} \mathrm{C}$ in a tissue culture incubator $\left(5 \% \mathrm{CO}_{2}\right)$ for up to 60 hours. For those cultures removed from the $\mathrm{CO}_{2}$ environment for time-lapse recording of neural crest migration, $20 \mathrm{mM}$ Hepes was added to the culture medium to maintain $\mathrm{pH}$. For those explants that were not exposed to time-lapse videomicroscopy, the distribution of DiI-labeled neural crest cells was recorded photographically after 16, 24 and 48 hours intervals in culture.

\section{Lectin treatment of explants}

For some experiments $(n=28)$, the explants were treated with the lectin peanut agglutinin (PNA;Vector) at concentrations ranging from 10 to $200 \mu \mathrm{g} / \mathrm{ml}$. The explants were pretreated by soaking in a solution of the lectin in Ringer's solution for 1 hour at room temperature and then positioned on the Millicells. The same concentration of PNA was added to the culture medium, allowing a continuous exposure of the explant to PNA during the culture period. The culture medium was not changed subsequently. In the cultures subjected to time-lapse microscopy, the addition of $20 \mathrm{mM}$ Hepes to the culture medium prior to videomicroscopy proved critical. When Hepes was omitted from the PNAtreated cultures that were removed from the $\mathrm{CO}_{2}$ environment, the pattern of neural crest migration appeared normal, suggesting that $\mathrm{pH}$ changes influenced PNA binding. Two control experiments were performed: (1) some explants were treated with another lectin with a different sugar specificity, wheat germ agglutinin (WGA; Vector) at 50 to 100 $\mu \mathrm{g} / \mathrm{ml}$ in the same manner as described above with PNA lectin; and (2) the explants were exposed to PNA that had been preabsorbed with its sugar hapten, galactose $(500 \mathrm{mM})$ for 1 hour. This solution was spun at $100,000 \mathrm{~g}$ for 1 hour; the supernatant was then removed, lyophilized and added to the culture medium.

\section{Immunocytochemistry}

In most cases, immunocytochemistry was performed while the trunk explants remained attached to the Millicell inserts. Culture medium was removed from beneath the culture inserts, the explants were rinsed with $0.1 \mathrm{M}$ phosphate buffer (PB; $\mathrm{pH} 7.3$ ), and then fixed in $4 \%$ paraformaldehyde in $0.1 \mathrm{M}$ phosphate-buffered saline (PBS; $\mathrm{pH}$ 7.4) overnight. The fixed explants were rinsed $3 \times 10$ minutes with PBS before primary antibodies were applied. HNK-1 antibody (ATCC) was applied as an undiluted hybridoma supernatant; an antibody against T-cadherin, kindly provided by Dr Diana Moss, was applied at $1: 50$ in $\mathrm{PBS} / 0.1 \% \mathrm{BSA}$; antibody against chick laminin was obtained from Developmental Studies Hybridoma Bank maintained by the Department of Pharmacology and Molecular Sciences at John Hopkins University
School of Medicine, Baltimore, MD, and the Department of Biology at the University of Iowa, Iowa City, IA, under contract number NO1HD-2-3144 from the NICHD; a neurofilament antibody (RMO 270.3; (Lee et al., 1987) was used to identify neurons and axons. Usually,
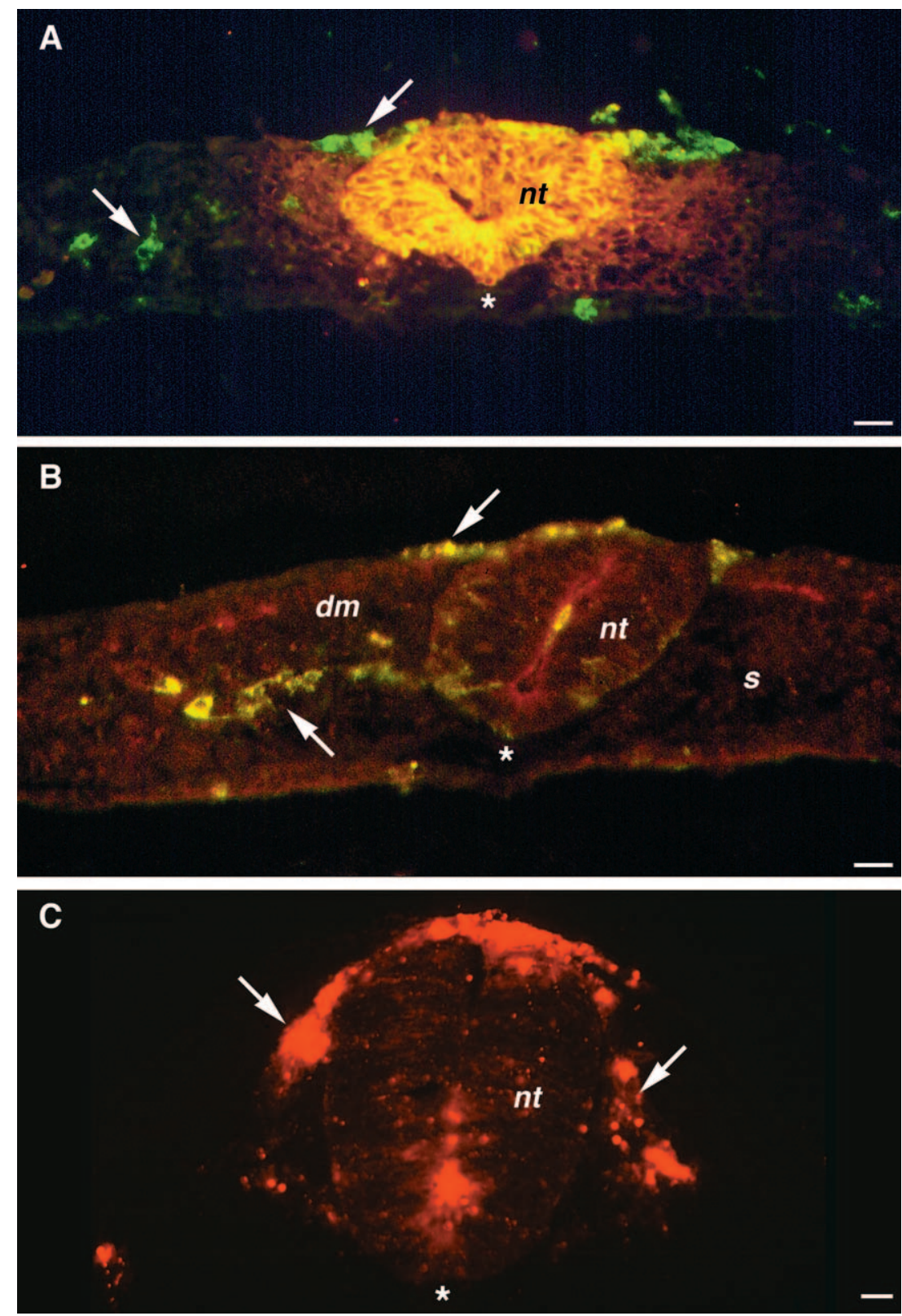

Fig. 2. Transverse sections through trunk explants show that neural tube and somitic morphology is preserved after 24 hours in culture. Neural crest cells migrate along normal pathways. (A) $10 \mu \mathrm{m}$ section through mid-explant, double-labeled with DiI and HNK-1 antibody. Arrows mark migrating neural crest cells that have recently emigrated from the neural tube and some cells within the somitic sclerotome. nt, neural tube. (B) $10 \mu \mathrm{m}$ section through mid-explant, labeled with $\mathrm{N}$-cadherin (red) and HNK-1 (green-yellow) antibodies. N-cadherin staining encircles the lumen of the neural tube (nt) and is present in the dermomyotome (dm). Arrows mark HNK-1positive neural crest cells, between the neural tube and somites, and in the sclerotome. (C) $10 \mu \mathrm{m}$ section through an intact embryo, at the same level as the explanted region, labeled with DiI and incubated for 24 hours. Arrow marks DiI-labeled neural crest cells that have emerged from the neural tube to migrate within the sclerotome. Note that the neural tube appears larger and more developed but the overall pattern of migration is similar to that seen in the explants. *, notochord; s, sclerotome; nt, neural tube; $\mathrm{dm}$, dermomyotome. Scale bars, $20 \mu \mathrm{m}$. 
antibodies were applied both below the culture inserts (in the same way the culture medium was applied) and over the dorsal surface of the explants, submerging the explants in antibody solution. Primary and secondary antibody incubations typically extended for 2 days to allow adequate penetration. After $3 \times 10$ minute rinses with PBS, secondary antibodies were added: (1) FITC-goat-anti-mouse IgM for the HNK-1 antibody; (2) RITC-goat-anti-rabbit IgG for the Tcadherin antibody; and (3) FITC-goat-anti-mouse IgG for the antilaminin and anti-neurofilament antibodies. All secondary antibodies were diluted 1:100 in PBS/0.1\% BSA. Following a final series of rinses with PBS, the labeled explants were viewed and photographed using a Zeiss Axiovert microscope equipped with fluorescence optics.

To examine morphological development and the position of neural crest cells in a transverse view, explants grown in culture for 24-36 hours were rinsed and fixed as described above. Explants were carefully removed from the culture insert membrane, rinsed in $0.1 \mathrm{M}$ $\mathrm{PB}$ and prepared for cryostat sectioning. Transverse sections were cut at $10 \mu \mathrm{m}$ throughout the length of 10 explants and affixed to uncoated slides. In some cases, sections were incubated in HNK-1 or Ncadherin antibodies (FA-5; Sigma) overnight at room temperature, followed by a fluorescently tagged secondary antibody for 2 hours at room temperature. Sections were then rinsed several times with PBS, mounted in Gel/Mount (biomeda) and coverslipped.

\section{Time-lapse videomicroscopy}

After 16 hours in culture, DiI-labeled normal explants $(n=15)$ and PNA-treated explants $(n=5)$ were followed by low-light-level videomicroscopy, using a SIT camera and an epi-fluorescence filter set designed for rhodamine. Prior to initiation of filming, a few labeled neural crest cells had migrated into the rostral regions of the most rostral somites in the explant. To prevent dehydration while collecting the time-lapse sequences, sterile water was added to the unfilled wells in the six-well culture plate and the entire plate was sealed with parafilm. The plate was then placed on the stage of a Zeiss Axiovert microscope (LD Achroplan 40× long-working-distance objective), equipped with an enclosed warming incubator that maintained the cultures at $38^{\circ} \mathrm{C}$ for the duration of time-lapse filming, with some mild temperature fluctuations. Images were recorded onto a video optical disc recorder (OMDR, Panasonic 3038), using a light-intensifying camera (Hamamatsu SIT) and image processor (Imaging Technology 151), using the VidIm software package (Belford, Stollberg, Fraser, unpublished). VidIm controlled the shutters (UniBlitz, model D122) so that fluorescence images were taken either every 2 or 4 minutes and bright-field images every 2 hours, for up to 48 hours. The plane of focus was adjusted every $4-6$ hours.

\section{Time-lapse data analysis}

The distances and rates of migration were quantified in selected cells in the time-lapse films of both normal and PNA-treated explants. Representative cells were selected based on the following criteria: (1) cells that were well-labeled with DiI and (2) cells whose cell bodies were easily recognizable from the time of their emergence from the neural tube through their migration within the somites. To record the cell trajectories, acetate film was placed over the video monitor, and the OMDR was advanced and halted to permit a single cell to be followed over time. Individual cell trajectories were made by marking each cell's position on the acetate at half-hour intervals for 7-24 hours. The 'mean rate of migration' was defined as the distance each cell traversed per hour in any direction $(\mu \mathrm{m} /$ hour \pm s.e.m.). The net distance of migration for each cell was determined by measuring the straight-line distance from the point of initiation of movement to the point that marked its furthest extent of migration within the somite. Thus, net distance measurements only included forward movements and did not measure the total path lengths, which would include backward or lateral components. The 'net hourly distance of migration' was determined by dividing the net distance of migration by the total time observed. Statistical analyses $(t$-tests) were done on a Macintosh computer using the Statview 512 statistical package. Images were digitized from the OMDR using the VidIm package and transferred to a Macintosh for processing using Adobe Photoshop.

\section{Neural crest cultures}

Primary neural crest cell cultures were prepared from Japanese quail embryos (Coturnix coturnix japonica) at developmental ages corresponding to chick stages $13-15$ and plated on a fibronectin substratum, as previously described (Lallier and Bronner-Fraser, 1991). Isolated neural tubes were pretreated with PNA (50 and $100 \mathrm{mg} / \mathrm{ml}$ ); the same concentration of PNA was added to the culture medium. As controls, untreated cultures were incubated in parallel with the PNAtreated cultures. Neural crest cell cultures were examined at 12-24 hours in vitro.
Fig. 3. DiI-labeled neural crest cells are found in the rostral but not caudal somitic regions in typical trunk explant after 36 hours in culture. Migration proceeds in a rostral-to-caudal manner in the explant, with greater numbers of labeled cells found in the more rostral somites. The pattern and timing of migration is similar to that observed in intact embryos. (A) Low magnification fluorescence micrograph of trunk explant. (B) Higher magnification of boxed area in A shows that DiI-labeled neural crest cells are found exclusively in the rostral somite. nt, neural tube; $r$, rostral somite; c, caudal somite. Scale bar, $20 \mu \mathrm{m}$.
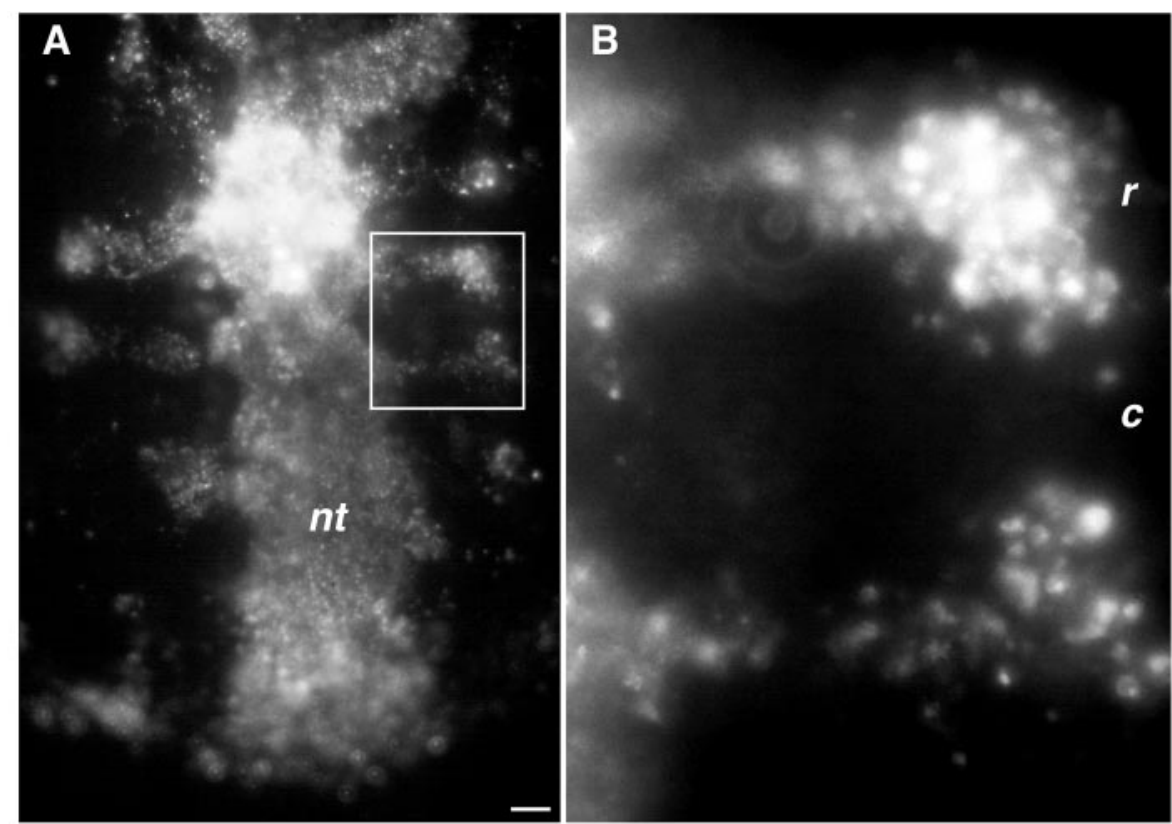


\section{RESULTS}

\section{Normal development in explant cultures}

To verify that development occurred normally in our paradigm, we characterized some morphological and molecular aspects of the trunk explants. Immediately after placement into culture, the neural tubes exhibit their characteristic cylindrical morphology and DiI labeling is confined to the neuroepithelium (Fig. 1). The somites appear indistinguishable from those seen in the intact embryo, being cuboidal in shape and having well-defined clefts between them (Fig. 1A). Transverse sections through explants after 24 hours in culture reveal that the neural tube and somites maintain their distinct morphology and continue to differentiate (Fig. 2). The dermomyotome and sclerotome can be visualized as separate somitic regions and HNK-1-immunoreactive neural crest cells are visible, migrating along normal pathways. The transverse sections show, however, that the neural tubes and somites are somewhat compressed and smaller by approximately half than those in intact embryos (compare Fig. 2A,B to C). The compression was most apparent at the rostral and caudal margins of the explants, where the initial excision from the embryo occurred. Therefore, analyses were typically performed in the mid-region of the explants. The morphology of the neural tube and somites appears relatively unchanged between 24 and 48 hours of explantation. After 60 hours in culture, the borders between different tissue types become difficult to resolve as cells spread and proliferate.

We determined the pattern and time course of neural crest migration by examining the emergence of DiI-labeled cells from the neural tube. A few DiI-labeled neural crest cells leave the neural tube by 16 hours after explantation and their number steadily increases with time. After 36 hours (Fig. 3), a segmental distribution of DiI-labeled cells in the somites is clearly visible, with labeled cells seen within the rostral but not caudal regions of consecutive somites. Migration progresses in a rostrocaudal sequence in the explants, with greater numbers of DiI-labeled cells in the more mature, rostral somites. Both the pattern and the rostrocaudal progression of neural crest migration in explants are similar to those observed in intact embryos, though the timing is delayed by 6 to 12 hours.

To confirm that the DiI-labeled cells in the explants were neural crest cells, we used HNK-1 immunoreactivity to mark this cell population (Tucker et al., 1984). In whole-mounted explants, HNK-1-immunoreactive neural crest cells are selectively localized within the rostral sclerotomes (Fig. 4A). HNK-1 immunostaining also is visible in neural tube cells, as is seen in normal embryos. This is not surprising given that this antibody labels numerous adhesion molecules, including some forms of N-CAM (Kruse et al., 1984).
Table 1. Mean rates and net hourly distances of migration for normal and PNA-treated explants

\begin{tabular}{|c|c|c|c|c|}
\hline & Location & $\begin{array}{c}\text { Mean rate } \\
\text { of migration } \\
(\mu \mathrm{m} / \mathrm{hr} \pm \text { sem })\end{array}$ & $\begin{array}{l}\text { Net hourly } \\
\text { distance of } \\
\text { migration } \\
(\mu \mathrm{m})\end{array}$ & $\begin{array}{c}\text { Total time } \\
\text { observed } \\
\text { (hour) }\end{array}$ \\
\hline \multicolumn{5}{|l|}{ Normal } \\
\hline Cell 1 & $\mathrm{r}$ & $10.2 \pm 1.5$ & 4.7 & 8.5 \\
\hline Cell 2 & $\mathrm{r}$ & $12.6 \pm 2.0$ & 6.4 & 7.0 \\
\hline Cell 3 & $\mathrm{r}$ & $12.6 \pm 1.8$ & 6.4 & 7.0 \\
\hline Cell 4 & $\mathrm{r}$ & $11.8 \pm 1.0$ & 7.0 & 14.0 \\
\hline Cell 5 & $\mathrm{r}$ & $11.2 \pm 1.3$ & 7.2 & 14.5 \\
\hline Cell 6 & $\mathrm{r}$ & $14.4 \pm 1.2$ & 4.7 & 17.5 \\
\hline Cell 7 & $\mathrm{r}$ & $10.6 \pm 1.6$ & 6.8 & 12.5 \\
\hline Cell 8 & $\mathrm{r}$ & $11.1 \pm 1.0$ & 7.4 & 12.5 \\
\hline mean & & $11.8 \pm 0.5$ & $6.3 \pm 0.4 * * *$ & \\
\hline \multicolumn{5}{|l|}{ PNA } \\
\hline Cell P1 & $\mathrm{r}$ & $7.2 \pm 1.1$ & 3.1 & 18.8 \\
\hline Cell P2 & $\mathrm{r}$ & $8.8 \pm 0.7$ & 4.2 & 15.3 \\
\hline Cell P3 & $\mathrm{r}$ & $5.9 \pm 0.8$ & 3.4 & 22.8 \\
\hline Cell P4 & $\mathrm{c}$ & $13.2 \pm 1.6$ & 2.4 & 24.0 \\
\hline Cell P5 & $\mathrm{c}$ & $9.3 \pm 2.1$ & 2.2 & 14.3 \\
\hline Cell P6 & $\mathrm{c}$ & $12.3 \pm 1.6$ & 2.0 & 9.0 \\
\hline mean & & $9.5 \pm 1.2$ & $2.9 \pm 0.3 * * *$ & \\
\hline
\end{tabular}

Mean rate of migration represents the mean distance traversed by the cells, including lateral and backwards excursions, per hour. No statistically significant difference exists between the mean rates of migration of cells in normal and PNA-treated explants.

Net hourly distance of migration represents the straight-line distance from initiation of migration to the furthest point of migration, divided by the total time observed. Significant differences were observed between cells in normal and PNA-treated cultures with respect to the net hourly distances of migration (***, $P<0.001)$.

Cells 1-6: trajectories shown in Fig. 6; Cell 7: blue cell in Fig. 5; Cell 8: yellow cell in Fig. 5. Cell P1: rostrally localized cell in Fig. 8; Cell P4: caudally localized cell in Fig. 8.

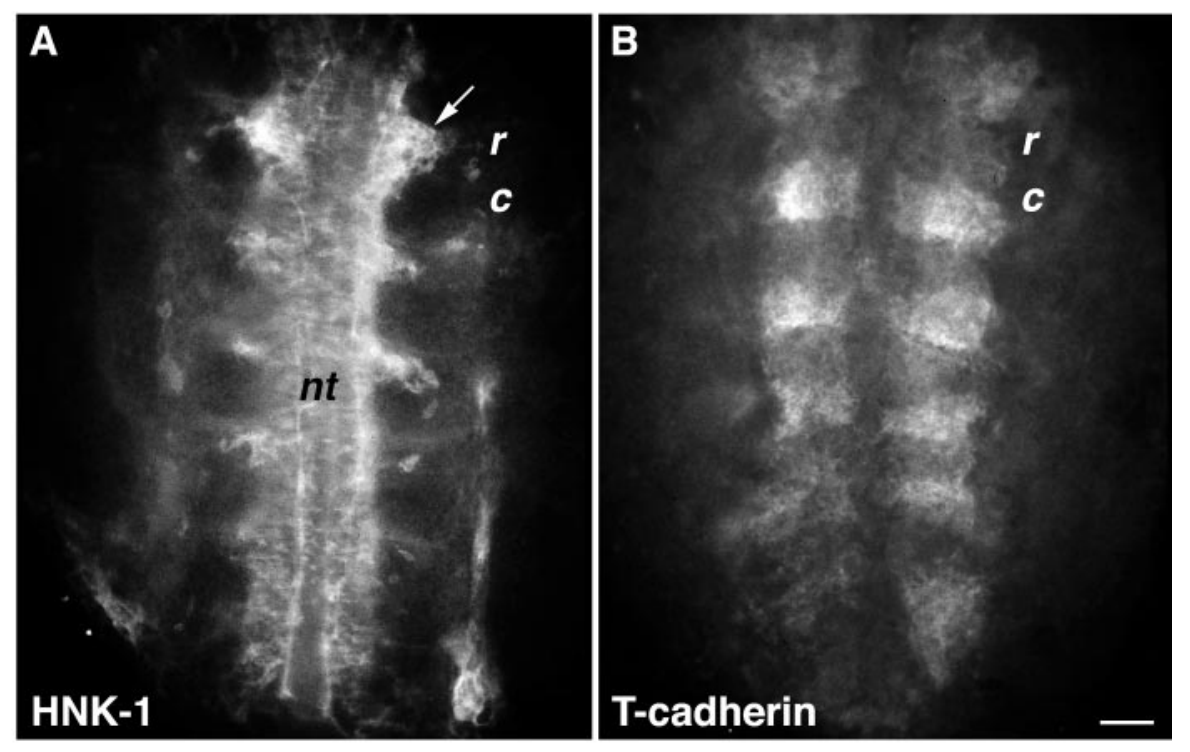

Fig. 4. Antibody labeling of trunk explants, after 24 hours in culture, illustrates the distribution of HNK-1-immunoreactive neural crest cells and T-cadherin, a molecule selectively distributed in the caudal somite. (A) HNK-1 antibody labels neural crest cells (arrow) in the rostral (r) somites as well as the neural tube cells (nt) in trunk explants. (B) T-cadherin is distributed in the caudal (c) but not rostral regions of the somites in trunk explants, as seen in the same field as A. Scale bar, $50 \mu \mathrm{m}$. 
Double-labeling using DiI and HNK-1 antibody revealed colocalization of these two markers to migrating neural crest cells in the explants. In transverse sections through explants after 24 hours in culture, neural crest cells are distributed within the somitic sclerotome (Fig. 2A,B), reminiscent of their position in intact embryos (Fig. 2C).

Because motor axons also extend from the neural tube, it is conceivable that application of DiI prior to neural crest migration could label axons in addition to migrating neural crest cells, thus complicating our analysis. To determine whether axons extended during the first 24 hours of the culture period, we examined their distribution by labeling the explants with an anti-neurofilament antibody (Lee et al., 1987). As expected, several neurofilament-positive cells were distributed in the neural tube. A few neurofilament-positive/DiI-labeled cell bodies were observed in the rostral sclerotome (not shown), suggesting that some neural crest cells had begun to differentiate into neurons. These cells occasionally had one or two stubby processes emanating from their somas. We failed, however, to find neurofilamentpositive axons extending from the neural tube. This suggests that the DiI-labeled cellular elements in the explants are exclusively neural crest cells.

To characterize somitic development at the molecular level, we examined the distribution of some molecules known to be selectively distributed within the somites. Tcadherin, a member of the cadherin family of cell adhesion molecules previously shown to be localized to caudal sclerotomal cells (Ranscht and Bronner-Fraser, 1991), is found only in the caudal portions of somites in the explants (Fig. 4B). In addition, N-cadherin is localized within the dermomyotome and encircling the lumen of the neural tube (Fig. 2B), typical of its in vivo distribution (Hatta et al., 1987). Laminin is observed in the basal laminae surrounding the neural tube, epidermis and dermomyotome, and is uniformly distributed within the sclerotome (not shown), as described previously in intact embryos (Krotoski et al., 1986).

Taken together, these results demonstrate that the explants develop normally during the course of neural crest cell migration, with only a few hours delay in migration compared to intact embryos. Furthermore, the pattern of neural crest migration appears indistinguishable from that in intact embryos. These data suggest that this novel explant system reliably mimics the in vivo situation, thus providing an accessible bioassay for further experiments.

\section{Time-lapse videomicroscopy of neural crest migration.}

After 16 hours of culture, explants $(n=15)$

B were selected for time-lapse recording and mounted on an inverted epi-fluorescence microscope equipped with a warming incubator. The best recordings were obtained from explants with a few well-labeled neural crest cells that were just beginning to enter the somites. Typically, images were collected every 2 minutes for $24-48$ hours, using a SIT camera.

Time-lapse recordings show that migration proceeds in a segmental manner from its initiation to its conclusion, with neural crest cells entering the rostral sclerotome from the inter-
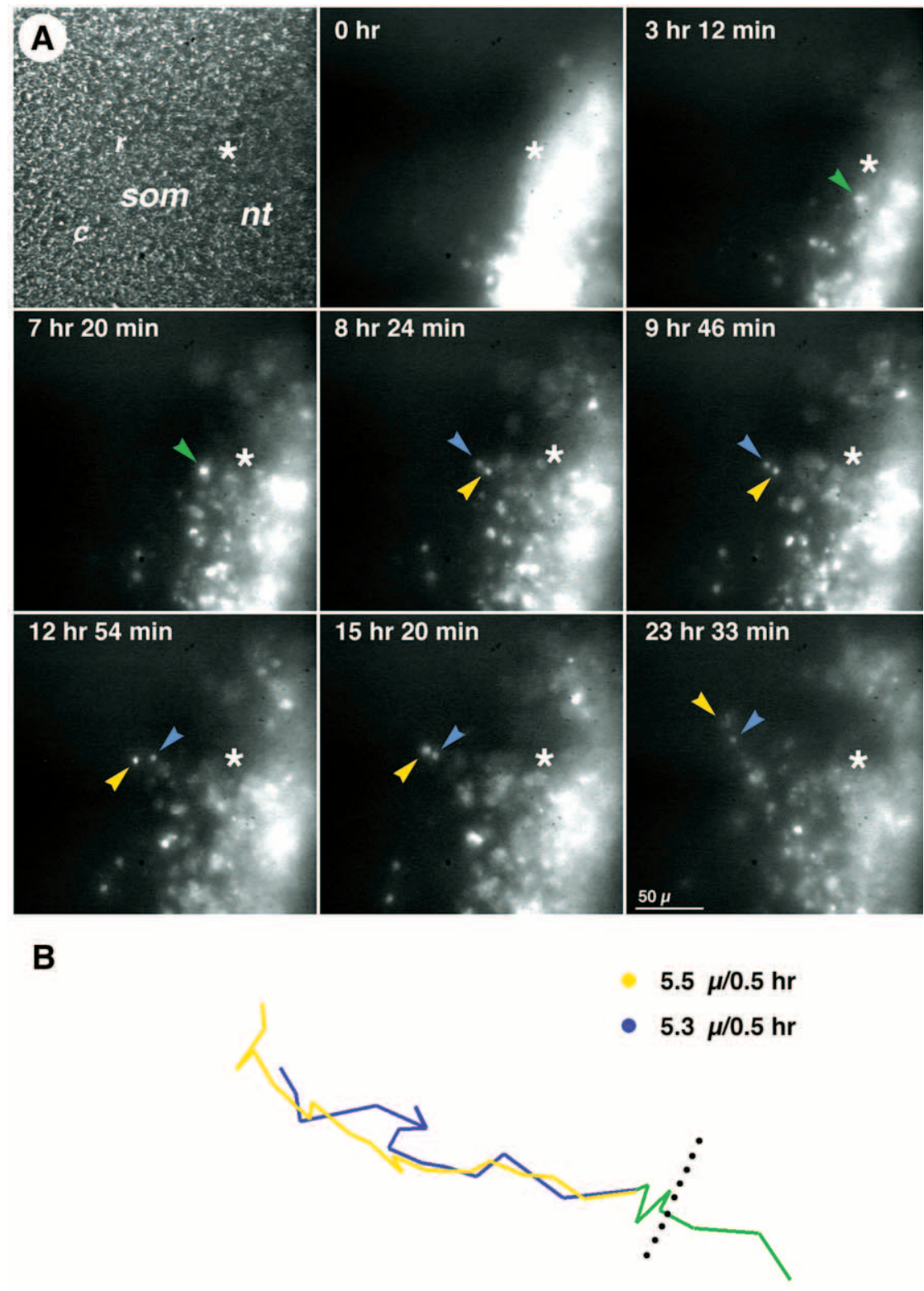

$20 \mu$

Fig. 5. Time-lapse sequences of normal neural crest migration in trunk explant.

(A) Phase image of the trunk explant and selected frames from a series of fluorescence images collected every two minutes. The green arrow marks a single cell emerging from the neural tube. At the point where two daughter cells can be resolved, yellow and blue arrows mark these clonally related cells. (B) Migration trajectories of the marked cells (blue and yellow arrows). Table 1 lists mean rates and net hourly distances of migration: blue-marked cell is Cell 7; yellow-marked cell is Cell 8. The dotted line delineates the border between the neural tube and somites. som, somite; nt, neural tube; r, rostral; c, caudal; *, marks border between neural tube and somite. 
1

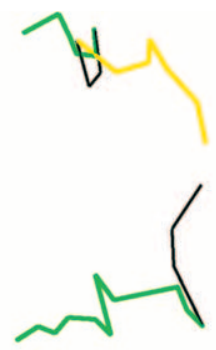

3

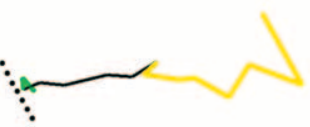

4

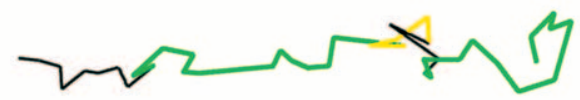

5

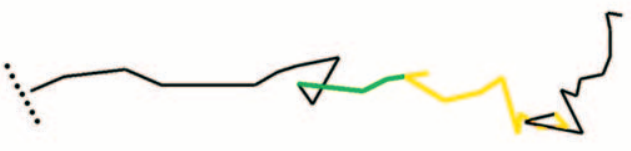

6

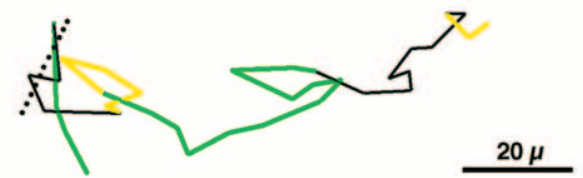

Fig. 6. Migratory trajectories of 6 individual neural crest cells followed in trunk explants over time. Each trajectory begins on the left; dotted line marks the border between the neural tube and somites. Tracking of cells 1, 2 and 4 began after these cells had emigrated from the neural tube and entered the somite. Cells 3, 5 and 6 were tracked beginning at or near their emergence from the neural tube. Cells exhibit rather complicated patterns of migration, moving forward, backward and laterally. Changes in colors of the trajectories are added to aid in visualization as these complex patterns overlap. Mean rates and net hourly distances of migration for these cells are listed in Table 1.

somitic border and migrating in an episodic fashion (Fig. 5). The first few DiI-labeled neural crest cells migrate into the intersomitic space, an extracellular matrix-rich region between the somites. Shortly thereafter, some neural crest cells invade the rostral half of the sclerotome, both from the intersomitic space and from the cells newly emerging from the neural tube. The migrating cells do not move uniformly; instead, they move haltingly in three to four distinct streams. The caudal sclerotome was always devoid of DiI-labeled cells. In a few cases, labeled cells initially adjacent to the caudal sclerotome were seen moving in a rostral direction along the neural tube until they reached the rostral half-somite, where they then turned and entered. This behavior is similar to that inferred from previous analyses of quail/chick chimerae (Teillet et al., 1987).

By examining the recordings of the migrating cells, we observed several new aspects of neural crest migratory behavior. First, the migration was more coordinated than expected. Neighboring cells often maintained close contact with each other as they migrated. Small groups of 2-4 cells traveled together, separated at times by short distances of two
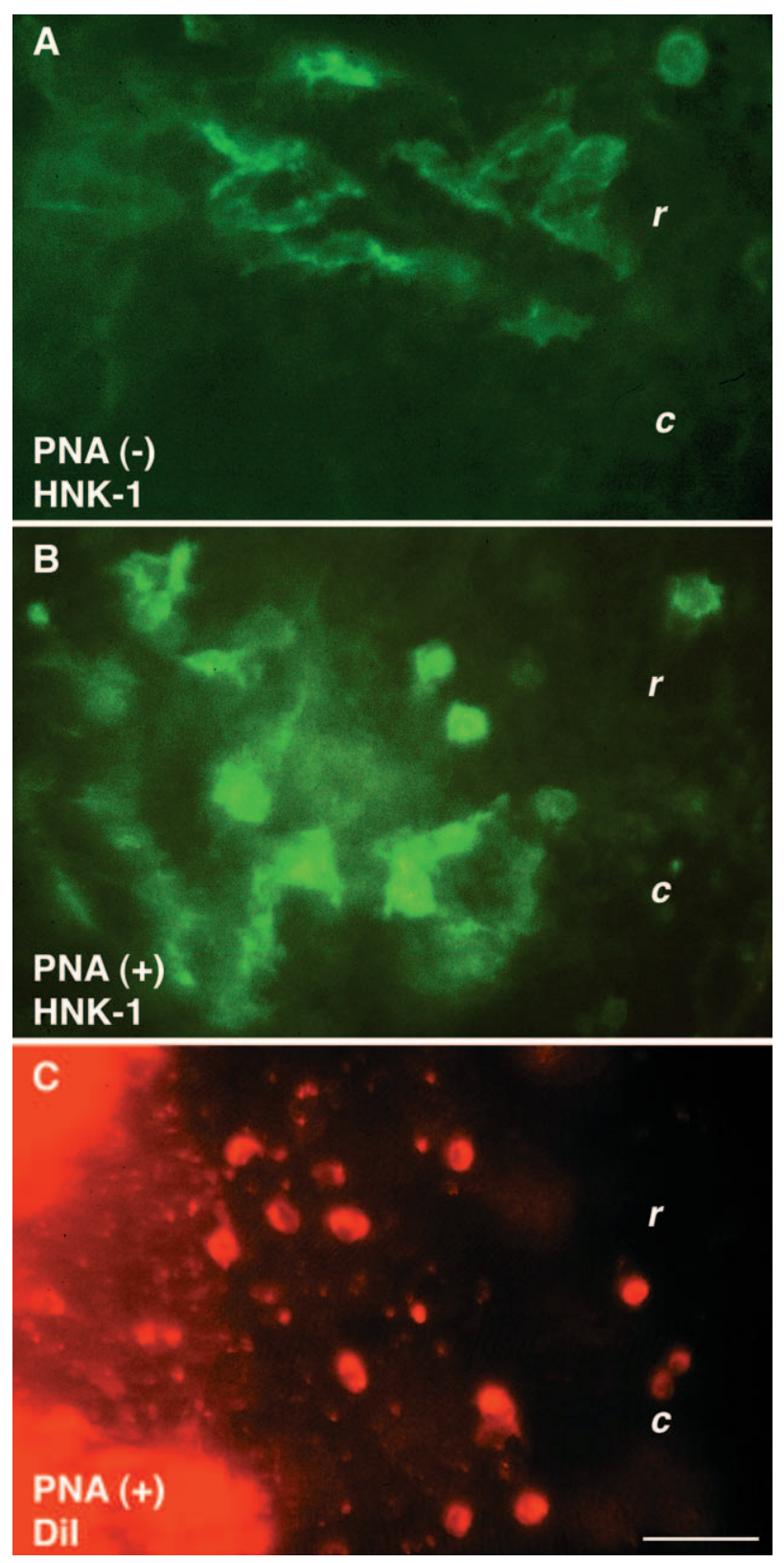

Fig. 7. Trunk explants treated with the lectin peanut agglutinin (PNA), after 36 hours in culture. The photomicrographs illustrate one somite length. With PNA treatment, neural crest cells are found in both the rostral and caudal regions of the somites. (A) A control explant, to which no lectin was added, shows HNK-1-

immunopositive neural crest cells in their typical location in the rostral somite. (B) An explant, treated with PNA and stained with the HNK-1 antibody, shows neural crest cells distributed in both rostral and caudal halves of the somite. (C) An explant treated with PNA shows DiI-labeled neural crest cells in both the rostral and caudal somite. r, rostral; c, caudal. Scale bar, $20 \mu \mathrm{m}$.

cell-body diameters but then reapproximating (Fig. 5). Although the resolution of our time-lapse movies did not allow us to visualize fine cellular processes reliably, occasionally we observed small extensions between cells. These observations of filopodia suggest that physical contacts between neural crest cells may be maintained even when cells are not near- 
neighbors. Cell division continued during the course of neural crest migration. For example, an individual cell that moved from the neural tube into the rostral somite divided to produce two progeny (Fig. 5). Interestingly, these daughter cells remained closely associated during their subsequent migration and essentially followed the same migratory trajectory.

To better understand the migratory behavior of individual neural crest cells, we selected two representative films and tracked the behavior of eight randomly selected cells. Cell tracking was discontinued when the labeled cells could no longer be distinguished due to intermixing with other labeled cells, decreased fluorescence due to cell division, or movement out of the plane of focus. Plots of the individual cell positions as a function of time (Fig. 6) reveal the details of the trajectories. Each cell examined migrated in a directional fashion. Although some cells exhibited a simple pattern of relatively linear movement from the neural tube through the somite, most cells displayed migratory patterns that were tortuous and punctuated by complicated turns. In all cases, there was some backward movement in addition to the overall forward direction of migration.

We quantified the mean rates of cell migration for the eight representative cells by measuring their total path length, including all backwards and lateral excursions. Five of these cells were followed from the time of emigration from the neural tube continuously through the course of their migration through the somites; the tracking of three other cells began as they entered the somites. The migratory rates of all eight cells were similar, ranging from $10-14 \mu \mathrm{m}$ per hour (Table 1; Figs 5 and $6)$. The net hourly distance of migration ranged from approximately 5-7 $\mu \mathrm{m}$ (Table 1). Thus, the typical cell traversed approximately $50 \mu \mathrm{m}$ of the somite (75-100 $\mu \mathrm{m}$ lateral dimension) in 8 hours. It appears that migrating neural crest cells move at a relatively uniform rate during the course of migration through the somites, as cells that were followed for shorter periods (7-8.5 hours; cells no. 1-3 in Fig. 6) displayed mean migration rates comparable to cells followed for longer times (12.5-17.5 hours; cells no. 4-6 in Fig. 6).

\section{PNA lectin disrupts the segmental pattern of neural crest migration.}

Peanut agglutinin-binding glycoproteins localized in the caudal sclerotome have been shown to cause axon collapse in vitro (Davies et al., 1990). Because both axons and neural crest cells move through the rostral sclerotome, we tested if PNA could alter the segmental pattern of neural crest migration through the somites. Explant cultures were exposed to PNA by preincubation and addition to the culture medium. To visualize the pattern of neural crest cell migration, the neural tube was prelabeled with DiI or the explant was poststained with the HNK1 antibody after 16-36 hours in culture. We used PNA concentrations ranging from 10 to $200 \mu \mathrm{g} / \mathrm{ml}$. No effect was seen at the lowest concentration $(10 \mu \mathrm{g} / \mathrm{ml})$; whereas, the highest concentration $(200 \mu \mathrm{g} / \mathrm{ml})$ caused distortion of the tissue. Intermediate concentrations ( 50 to $100 \mu \mathrm{g} / \mathrm{ml}$ ) produced specific effects on neural crest migration without affecting tissue integrity in the explant.

In contrast to untreated explant cultures (Fig. 7A), neural crest cells were found in both the rostral and the caudal portions of the sclerotome in each of the PNA-treated explants (Fig. 7B,C). Approximately equivalent numbers of cells were observed throughout the rostrocaudal extent of the sclerotome. Not only the distribution but also the morphology of some of the cells appeared quite different. Rather than being elongated and aligned mediolaterally, some of the treated neural crest cells were rounded and had less of an obvious orientation. In control explants, treated with no lectin ( $n=30$; Fig. 7A), with wheat germ agglutinin (WGA) a lectin with different specificity $(n=15$; not shown), or with PNA preabsorbed with galactose ( $n=15$; not shown), neural crest cells migrated in their typical segmented pattern, exclusively through the rostral sclerotome.

To better define the effects of the lectin on neural crest migratory behavior, individual cells in PNA-treated explants $(n=5)$ were followed using time-lapse videomicroscopy. Similar to the results seen in static images, neural crest cells in PNA-treated explants entered both the rostral and caudal regions of the somite (Fig. 8). The first neural crest cells entered rostrally whereas migration into the caudal region began a few hours later. Neural crest cells seemed to migrate directly from the neural tube into the caudal somite. We did not observe neural crest cells migrating in the stream-like fashion as seen in the normal trunk explants and, overall, the migratory behavior of neural crest cells appeared more chaotic. At times, neural crest cells made extreme changes in their trajectory (see Fig. 8C). We did observe, however, that some cells maintained close contacts with neighboring cells during their navigation in the somite, traveling in small groups. Once, we viewed a caudally-located cell crossing into the rostral region of the somite, but never saw cells moving from the rostral to the caudal sclerotome. Thus, migrating cells remained in either the rostral or caudal portion once having entered that region.

We quantitated the migratory behavior of six selected neural crest cells in two PNA-treated explants. Three of the cells were located in the rostral somite and three in the caudal somite. Two representative cell trajectories are shown in Fig. 8B,C. These trajectories are somewhat similar to those recorded from cells in normal explants, comprising complex turns and combinations of directional changes. The mean rates of migration ranged from 6 to $13 \mu \mathrm{m}$ per hour, slightly lower than those in untreated cultures (Table 1). In some cases, cells exhibited bursts of migration at much higher rates than we had observed in the untreated explants. Cell P4 (see Fig. 8C; Table 1), for example, moved $34 \mu \mathrm{m}$ in 0.5 hours. In other cases, cells appeared to temporarily stall. We measured the net hourly distance of migration of the six cells, excluding the backward and lateral variations in movement. This measurement ranged from 2 to $4 \mu \mathrm{m}$ and was significantly lower $(P<0.001)$ than that measured in untreated explants (Table 1). The net distances covered in 8 hours ranged from 16 to $34 \mu \mathrm{m}$, with a mean of $23 \mu \mathrm{m}$, approximately half that covered by neural crest cells in the normal trunk explants. The migratory behavior of caudallylocalized neural crest cells was more disordered than their rostral counterparts. They made extensive backward movements; in two examples, they returned near the point where they initiated migration.

Although PNA-binding molecules have been localized to caudal sclerotomal cells, it is possible that PNA might directly affect neural crest cells. To test this possibility, we cultured isolated neural crest cells on a fibronectin substratum in the presence of PNA but in the absence of sclerotomal cells. Under these culture conditions, PNA had no obvious effects on the 
extent of neural crest migration compared to control cultures. In addition, there were no alterations in the morphology of the cultured cells (data not shown). This suggests that PNA does not affect neural crest cells directly but rather, exerts its effect by altering the molecular properties of the somitic environment.

\section{Discussion}

A fascinating question is what cellular and molecular mechanisms segment the migration of neural crest cells through the somites. Trunk neural crest cells as well as sensory and motor axons navigate exclusively through the rostral sclerotome (Keynes and Stern, 1984), generating the segmental organization of the peripheral nervous system. Previous studies suggest that cues inherent to the somites are responsible for this pattern. When a region of presomitic mesoderm was inverted rostrocaudally to reverse somite polarity, neural crest cells entered the original rostral portions of the somites (Bronner-Fraser and Stern, 1991). Furthermore, when pairs of rostral halves of somites were created, oversized dorsal root ganglia formed, suggesting that the molecular properties of the rostral half-somites allowed entry of additional neural crest cells (Stern and Keynes, 1987; Kalcheim and Teillet, 1989).

To explore the cell-cell interactions and molecular basis of neural crest migration through somites, we have developed an explant culture system. Our primary goal was to create a system that permits access to migrating cells, yet mimics the environment of the intact embryo. This contrasts with previous analyses of neural crest migration in vitro on two-dimensional substrata, since these studies can only suggest roles for single molecules or interactions. Our morphological and molecular analyses of the explants demonstrate that this system provides a normal bioassay of neural crest migration and somitic development that closely mimics the in vivo situation. The neural tube and somites maintain their structural integrity for approximately 2 days in culture and the somites progress from epithelial balls to segregated structures. Known molecular constituents of the somitic environment, such as T-cadherin, laminin and N-cadherin, were found in their typical locations in the explants, demonstrating that many molecular components of the somites remain preserved in this preparation. As in the intact embryo, neural crest cells migrate through the rostral portions of the somites in the explants. A few labeled neural crest cells entered the somites as early as 12-16 hours in culture, with additional cells entering them over the next 48 hours. This is analogous to the pattern of migration in intact embryos. Thus, the trajectory and numbers of neural crest cells appear normal in the explant, with a general developmental delay of 6-12 hours compared with intact embryos. Such delays are reportedly typical of explant and slice preparations.

Time-lapse analysis of DiI-labeled neural crest cells not only confirms the general patterns seen in static pictures but also reveals a number of new aspects of migration. The first few DiI-labeled neural crest cells emerge from the neural tube to enter the intersomitic space, as reported for the intact embryo (Loring and Erickson, 1987; Newgreen, 1989). Later, some labeled cells move laterally into the rostral somite. Other cells located between the neural tube and caudal somite shift rostrally to enter the rostral sclerotome, consistent with observations of Teillet and colleagues (1987). Although this behavior is likely to occur frequently, we observed it only on rare occasions because the intense labeling of the neural tube often obscures the visibility of immediately adjacent cells. These observations, together with results from grafting experiments (Teillet et al., 1987; Bronner-Fraser and Stern, 1991), provide strong support for the idea that neural crest cells migrate uniformly from the neural tube but that properties unique to the caudal sclerotome prevent neural crest migration.

The meandering trajectories of individual neural crest cells through the rostral sclerotome should not be taken as evidence for a lack of order to the migration. For example, as larger numbers of neural crest cells fill the rostral sclerotome, they form closely associated streams of cells. Perhaps more significant is the observation that neural crest cells travel in cohorts of 2-4 cells that stay closely associated as they migrate in the rostral somite. Small processes occasionally were observed between these cells. Such close contacts suggest that, in addition to interactions with the somitic milieu, communication between neural crest cells is potentially important for aligned and/or coordinated migratory behavior. At times, we observed examples of cell division as neural crest cells migrated through the somite. Even as their trajectories carried them apart, the daughter cells often returned to reestablish close contact during their navigation. This coordinated behavior raises the possibility that the cohorts of 2-4 cells may be clonally related. It is not known if the cohorts or the mitotic pairs diverge at some point to give rise to distinct derivatives or populate the same derivative.

Neural crest cells migrate at the rate of $10-14 \mu \mathrm{m}$ per hour. This is in the same range previously noted for neural crest migration on simple substrata (6-48 $\mu \mathrm{m}$ per hour; Rovasio et al., 1983). Although it is difficult to compare in situ migration with that observed on single ECM molecules, it is encouraging that similar migratory rates have been observed using such divergent approaches. Tracking cells over time, we observed changes in the trajectories of individual trunk neural crest cells that have not been noted previously. Because neural crest cells migrate forward, backward and sideways, the overall rate of migration observed here may be higher than that predicted by looking at their initiation and termination points alone.

Several molecules have been suggested to be responsible for the exclusion of neural crest cells from the caudal somite, based on their distributions or effects on cultured cells (Bronner-Fraser, 1993). PNA-binding molecules (Stern et al., 1986; Davies et al., 1990; Oakley and Tosney, 1991) are strictly localized to the caudal sclerotome. Somite extracts produce an abrupt collapse of growth cones when applied to chick sensory neurons in vitro and this activity is abolished by immobilized PNA (Davies et al., 1990). In addition, contact with caudal sclerotome cells in culture appears to impair the extension of motor axons (Oakley and Tosney, 1993). Taken together, these results implicate PNA-binding molecules as inhibitors of axon navigation through caudal sclerotome. Although their influence on trunk neural crest cell migration has not been tested previously, PNA-binding molecules exhibit the proper spatiotemporal localization to play a role. Interestingly, PNA labels other regions of the developing embryo from which neural crest cells are excluded (Tosney and Oakley, 1990; Oakley et al., 1994), suggesting that common inhibitory mechanisms may be involved.

We tested the effects of PNA on trunk neural crest migration by exposing explant cultures to the lectin and subsequently 
Fig. 8. Time-lapse sequences of neural crest migration in PNA-treated explants and migration trajectories of two representative cells, followed during their navigation in the somite. (A) Phase image of the trunk explant taken at initiation of time-lapse videomicroscopy plus selected frames from a series of fluorescence images, collected every four minutes. Arrow marks a cell in the rostral somite; arrowhead marks a cell in the caudal somite. (B) Migratory trajectory of the rostrally-located cell (P1 in Table 1) marked with arrow in A. Tracking began after the cell had emerged from the neural tube. (C) Migratory trajectory of the caudally-located cell (P4 in Table 1) marked with arrowhead in A. Tracking began after cell emerged from neural tube. Changes in color of the trajectories are added to aid in visualization. Mean rates and net hourly distances of migration listed in Table 1. nt, neural tube; som, somite; r, rostral; c, caudal; *, marks border between the neural tube and somite.
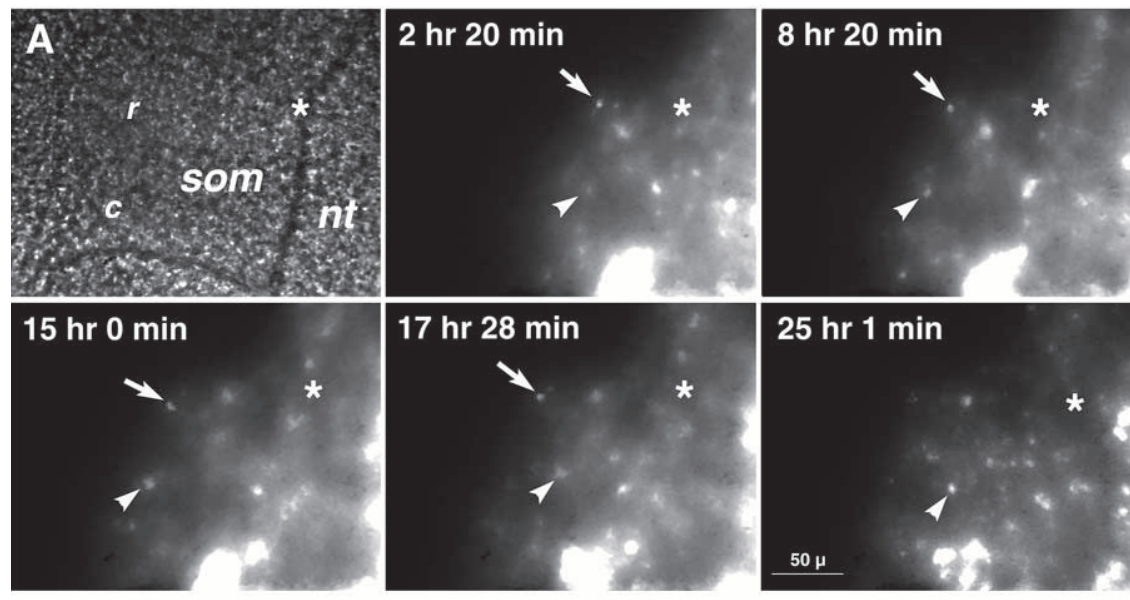

B

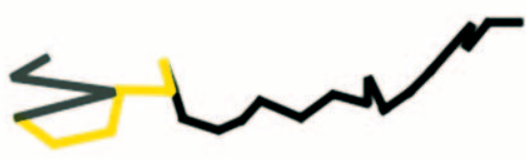

C $20 \mu$

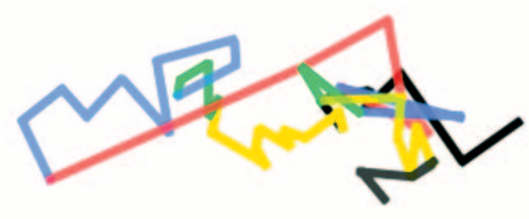

found neural crest cells in both rostral and caudal somitic regions. In contrast, control explants contained no neural crest cells in the caudal somite. There are interesting differences in the morphology of some neural crest cells in PNA-treated explant cultures compared with those in control cultures. Some cells are rounded and not directionally oriented, often separated from each other without apparent physical contact. It is not clear whether these effects are direct or indirect; PNA may effectively decrease the density of neural crest cells in the rostral somite. These changes in cell density could reduce cellcell contacts, thereby decreasing the likelihood of coordinated cell movements. Our time-lapse studies reveal that, in addition to its effects on the pattern of migration, PNA slows the rate of migration and decreases the net distance covered by both rostral and caudal neural crest cells. Interestingly, unlike rostrally-located cells, caudally-located neural crest cells made extensive backward movements. Thus, although the mean rates of migration of the caudally-localized cells are slightly faster than their rostral counterparts, the backtracking of caudallylocalized cells reduced their net distance of migration. Perhaps, this indicates that the caudally-localized neural crest cells have difficulty navigating in the 'foreign' territory of the caudal somite. This, together with the finding that neural crest cells enter the rostral sclerotome a few hours prior to those entering caudally, might reflect some rostrocaudal difference other than PNA-binding molecules, such as an attractive component within the rostral sclerotome. Alternatively, a disorienting cue present caudally could affect cell migratory behavior.
Although we cannot formally rule out the possibility that PNA may be affecting directly a cell surface component on neural crest cells, the finding that PNA does not alter migration in neural crest cultures makes this scenario unlikely. These results provide strong evidence that PNA-binding molecules in the caudal sclerotome play an inhibitory role in the spatial patterning of neural crest cells in somites.

The parallels between our results and those of previous studies (Davies et al., 1990) suggest that PNA-binding molecules influence both neural crest migration and axon navigation through the somites. Davies and colleagues (1990) have demonstrated that PNA binds two glycoproteins within the caudal sclerotome. Further characterization of these molecules is likely to provide insight into the molecular mechanisms underlying their inhibitory effect. Of course, these results do not rule out the possibility that other inhibitory or permissive molecules may also play a role in the segmentation of neural crest migration.

In this study, we have devised an explant culture system to analyze trunk neural crest migration in living specimens. By analyzing the dynamic aspects of cell movement, we not only have confirmed the results of previous static studies but also have discovered new properties of neural crest cell migration. The explant paradigm combines two significant advantages in that it allows manipulation of the molecular environment and permits the effects of the perturbation to be visualized. The finding that PNA causes an alteration in the segmental pattern of migration is the first functional demonstration of a specific 
set of molecules affecting the migration of trunk neural crest cells in situ. This paradigm provides direct access to the neural crest system, setting the stage for future experiments to test the function of prospective attractive and inhibitory molecules in neural crest migration. The natural setting provided by the explant cultures will help to decipher the interactions between different positive and negative factors in guiding these complex developmental events.

We dedicate this work to the memory of Dr Edmund Arbas. His great enthusiasm for his family, friends and science will be remembered. We thank Roham Zamanian and Jon Neri for excellent technical assistance. This work was supported by NIH/NRSA 09459 to C. E. K., by USPHS 15527 and a Muscular Dystrophy Association grant to M. B.-F., by a NIMH Silvio Conte Center grant to S. E. F. and A. C., and Beckman Institute Biological Imaging Center.

\section{REFERENCES}

Barber, R. P., Phelps, P. E. and Vaughn, J. E. (1993). Preganglionic autonomic motor neurons display normal translocation patterns in slice cultures of embryonic rat spinal cord. J. Neurosci.13, 4898-4907.

Bronner-Fraser, M. (1985). Alterations in neural crest migration by an antibody that affects cell adhesion. J. Cell Biol. 100, 327-332.

Bronner-Fraser, M. (1986). Analysis of the early stages of trunk neural crest migration in avian embryos using monoclonal antibody HNK-1. Dev. Biol. 115, 44-55.

Bronner-Fraser, M. (1988). Distribution and function of tenascin during cranial neural crest development in the chick. J. Neurosci.Res. 21, 135-147.

Bronner-Fraser, M. (1993). Environmental influences on neural crest cell migration. J. Neurobiol. 24, 223-247.

Bronner-Fraser, M. and Stern, C. D. (1991). Effects of mesodermal tissues on avian neural crest cell migration. Dev. Biol. 143, 213-217.

Bronner-Fraser, M., Wolf, J. J. and Murray, B. A. (1992). Effects of antibodies against N-cadherin and N-CAM on the cranial neural crest and neural tube. Dev. Biol. 153, 291-301.

Davies, R. J., Cook, G. M. W., Stern, C. D. and Keynes, R. J. (1990). Isolation from chick somites of a glycoprotein fraction that causes collapse of dorsal root ganglion growth cones. Neuron 4, 11-20.

Erickson, C. A. and Perris, R. (1993). The role of cell-cell and cell-matrix interactions in the morphogenesis of the neural crest. Dev. Biol. 159, 60-74.

Hamburger, V. and Hamilton, H. L. (1951). A series of normal stages in the development of the chick embryo. J. Morph. 88, 49-92.

Hatta, K., Takagi, S., Fujisawa, H. and Takeichi, M. (1987). Spatial and temporal expression pattern of $\mathrm{N}$-cadherin cell adhesion molecules correlated with morphogenetic processes of chicken embryos. Dev. Biol. 120, 215-227.

Kalcheim, C. and Teillet, M. A. (1989). Consequences of somite manipulation on the pattern of dorsal root ganglion development. Development 106, 85-93.

Keynes, R. J. and Stern, C. D. (1984). Segmentation in the vertebrate nervous system. Nature 310, 786-789.

Keynes, R. J. and Stern, C. D. (1988). Mechanisms of vertebrate segmentation. Development 103, 413-429.

Krotoski, D., Domingo, C. and Bronner-Fraser, M. (1986). Distribution of a putative cell surface receptor for fibronectin and laminin in avian embryo. $J$. Cell Biol. 103, 1061-1071.

Kruse, J., Mailhammer, R., Wenecke, H., Faissner, A., Sommer, I., Goridis, C. and Schachner, M. (1984). Neural cell adhesion molecules and myelin-associated glycoprotein share a common carbohydrate moiety recognized by monoclonal antibodies L2 and HNK-1. Nature 311, 153-155.

Lallier, T. E. and Bronner-Fraser, M. (1988). A spatial and temporal analysis of dorsal root and sympathetic ganglion formation in the avian embryo. Dev. Biol. 127, 119-132.

Lallier, T. E. and Bronner-Fraser, M. (1991). Avian neural crest cell adhesion to laminin: Involvement of divalent cation dependent and independent integrins. Development 113, 1069-1081.

LeDouarin, N. M. (1982). The Neural Crest. Cambridge University Press, Cambridge.

Lee, V., Carden, M., Schlaepfer, W. and Trojanowski, J. (1987). Monoclonal antibodies distinguish several differentially phosphorylated states of the two largest rat neurofilament subunits (NF-H and NF-M) and demonstrates their existence in the normal nervous system of adult rats. $J$. Neurosci. 7, 3474-3489.

Loring, J. F. and Erickson, C. A. (1987). Neural crest cell migratory pathways in the trunk of the chick embryo. Dev. Biol. 121, 220-236.

Newgreen, D. F. (1989). Physical influences on neural crest cell migration in avian embryos: Contact guidance and spatial restriction. Dev. Biol. 131, 136148 .

Newgreen, D. F. and Thiery, J. P. (1980). Fibronectin in early avian embryos: Synthesis and distribution along the migration pathways of neural crest cells. Cell Tissue Res. 211, 269-291.

Oakley, R. A. and Tosney, K. W. (1991). Peanut agglutinin and chondroitin-6sulfate are molecular markers for tissues that act as barriers to axon advance in the avian embryo. Dev. Biol. 147, 187-206.

Oakley, R. A. and Tosney, K. W. (1993). Contact-mediated mechanisms of motor axon segmentation. J. Neurosci. 13, 3733-3792.

Oakley, R. A., Lasky, C. J., Erickson, C. A. and Tosney, K. W. (1994) Glycoconjugates mark a transient barrier to neural crest migration in the chicken embryo. Development 120,103-114.

Ordahl, C. (1993). Myogenic lineages within the developing somite. In Molecular Basis of Morphogenesis, pp 165-176 (ed. M. Bernfield). New York: Wiley-Liss.

Perris, R., Krotoski, D., Lallier, T., Domingo, C., Sorrel, J. M. and Bronner-Fraser, M. (1991). Spatial and temporal changes in the distribution of proteoglycans during avian neural crest development. Development 111, 583-599.

Poole, T. J. and Thiery, J. P. (1986). Antibodies and synthetic peptides that block cell-fibronectin adhesion arrest neural crest migration in vivo. In Progress in Developmental Biology, Part B (ed. H. Slavkin). New York: Alan R. Liss Inc.

Ranscht, B. and Bronner-Fraser, M. (1991). T-cadherin expression alternates with migrating neural crest cells in the trunk of the avian embryo. Development 111, 15-22.

Rickmann, M., Fawcett, J. W. and Keynes, R. J. (1985). The migration of neural crest cells and the growth of motor axons through the rostral half of the chick somite. J. Embryol. Exp. Morph. 90, 437-455.

Rovasio, R. A., Delouvee, A., Yamada, K. M., Timpl, R. and Thiery, J. P. (1983). Neural crest migration: Requirements for exogenous fibronectin and high cell density. J. Cell Biol. 96, 462-473.

Serbedzija, G. N., Bronner-Fraser, M. and Fraser, S. E. (1989). A vital dye analysis of the timing and the pathways of neural crest cell migration. Development 106, 809-819.

Stern, C. D. and Keynes, R. J. (1987). Interactions between somite cells: the formation and maintenance of segment boundaries in the chick embryo. Development 99, 261-272.

Stern, C. D., Sisodiya, S. M. and Keynes, R. J. (1986) Interactions between neurites and somite cells: inhibition and stimulation of nerve growth in the chick embryo. J. Embryol. Exp. Morph. 91, 209-226.

Teillet, M., Kalcheim, C. and LeDouarin, N. M. (1987). Formation of the dorsal root ganglion in the avian embryo: Segmental origin and migratory behavior of neural crest progenitor cells. Dev. Biol. 120, 329-347.

Tosney, K. W. and Oakley, R. A. (1990) The perinotochordal mesenchyme acts as a barrier to axon advance in the chick embryo: implications for a general mechanism of axonal guidance. Exp. Neurol. 109, 75-89.

Tucker, G. C., Aoyama, H., Lipinski, M., Tursz, T. and Thiery, J. P. (1984). Identical reactivity of monoclonal antibodies $\mathrm{HNK}-1$ and $\mathrm{NC}-1$ : conservation in vertebrates on cells derived from the neural primordium and on some leukocytes. Cell Diff. 14, 223-230.

Weston, J. (1970). The migration and differentiation of neural crest cells. $A d v$. Morph. 8, 41-114.

(Accepted 14 August 1995) 